\title{
Supporting and Understanding Reflection on Persuasive Technology through a Reflection Schema
}

\author{
Fahri Yetim $^{1,2}$ \\ ${ }^{1}$ FOM University of Applied Sciences, Dept. of Information Systems, Cologne, Germany \\ fahri.yetimefom.de \\ ${ }^{2}$ University of Oulu, Dept. of Information Processing Science, Oulu, Finland
}

\begin{abstract}
Literature on persuasive technology acknowledges the importance of promoting reflection within design research and practice. This paper takes up a reflection framework suggested in previous research as assisting the reasoning of researchers, designers or other stakeholders concerning values, goals, actions, and their consequences in a project. It contributes to this research by demonstrating additional evidence for the applicability of the reflection framework by applying it to a published case. This work can guide researchers and practitioners by means of issues to be considered while reflecting on as well as communicating value-related aspects in a project, so that significant value choices and the rationale for actions taken to promote them are clear.
\end{abstract}

Keywords: Reflection, Discourse Ethics, Value Sensitive Design, Research Communication, Persuasive Technology

\section{Introduction and Background}

It is a widely shared view that being sensitive in setting design goals, choosing means as well as considering the values and rights of all relevant stakeholders ensure that ethically and morally relevant considerations inform the shaping of a system $[2,3,5$, $13,16]$. Reflection is necessary to challenge assumptions and values as well as for clarifying our understanding of what is good or bad, right or wrong [5,13]. Research in the context of persuasive technology investigates and suggests a set of principles, models and methods for the analysis, design and evaluation of such systems that aim at influencing people to change their attitudes and/or behaviors [10]. Previous research has argued that setting persuasion goals and chosen means to achieve them imply value assumptions and have consequences for those affected. They have emphasized the importance of reflection and user participation in the analysis, design and evaluation of persuasive systems $[7,9,11,12,15,17]$.

This paper takes up a reflection framework suggested in previous research as assisting the reasoning of researchers, designers or other stakeholders about values, goals, actions, and their consequences in a project [15]. This framework is informed by the reflective concepts of discourse ethics [4,5], - including different types of discourses such as pragmatic, ethical, and moral discourses, - and by other value-based 
argumentation approaches [1]. Previous publications related to this framework have argued that it can be used within the process of persuasive system development for several purposes, e.g., for supporting ideation, analysis, design, evaluation as well as publication of a system. However, the usage of the framework has so far only been partially demonstrated. For example, the framework provided guidance for the design of reflection support systems $[14,16]$ as well as of an argumentation-based design rationale application, a Rationale Browser, that implements several of the questions of the framework to enable reflections as well as to document the result of the reflections [6]. In addition, parts of the framework (i.e., aspects of the pragmatic discourse) were considered for the analysis of the communication of value sensitive design research, and demonstrated that some of the guidelines have been inherently followed by some researchers [18].

This paper extends the analysis perspective beyond pragmatic discourses and in addition considers ethical and moral discourses in order to offer an incremental contribution to the research. By applying the framework to a published case that communicates reflections on persuasive technology, this paper provides additional evidence for the applicability of the reflection framework within the practice of persuasive design research. Such an analysis of reflections can help persuasive system researchers and designers to clarify the value specific issues and significant choices, to understand the reflections and reasoning of research participants, as communicated by the researchers, as well as to identify issues that have been given no or little consideration.

In the following, we first introduce the relevant parts of the reflection framework, then present a proof-of-concept demonstration of its applicability by applying it to a published research article, and finally, provide some discussion and conclusions.

\section{The Reflection Framework}

Practical reasoning is the general human capacity for resolving, through reflection, the question of what one intends to do. In his discourse ethics, J. Habermas [4] distinguishes between the pragmatic, ethical and moral employment of practical reason and three types of practical discourses, i.e., pragmatic, ethical and moral discourses. The idea is that in practical situations the question of what one is to do can take on pragmatic, ethical, and moral meaning, requiring different kinds of answers for justifying choices among alternative available courses of action. Reflections on pragmatic discourse seek reasons for a rational choice of means in the light of fixed goals, or of rational assessments of goals in the light of existing value preferences. Ethical discourse involves reflection on what is good for oneself or for a cultural community. Finally, moral discourses seek what is "equally good for all" and thus just.

To provide further refined guidance for reflections in relation to these three types of discourses, previous research [15] has distinguished two usage options for discourses: for identifying ideas (identifying mode) and for evaluating decisions/regulations (checking mode). In addition, a set of critical questions for each discourse are provided to support the reasoning/reflection of researchers, designers or other stakeholders. 
J. Habermas [5] considers practical decisions to be legitimate if they result from a deliberative process that involves a fair consideration of the interests, values and valid norms. We consider persuasive system design research as a practice that has to deal with the practical, the good and the just. Consequently, its results can be considered legitimate if they are justified from the standpoint of pragmatic, ethical, and moral reasons, - a process requiring iterations between discourses in both identifying and checking modes for creating and examining ideas [16]. In this paper we limit our attention to the usage of discourses in the checking mode, as shown in Table 1, and leave the usage of discourses in the identifying mode to another paper.

Table 1. Discourses and related questions in the checking mode [15]

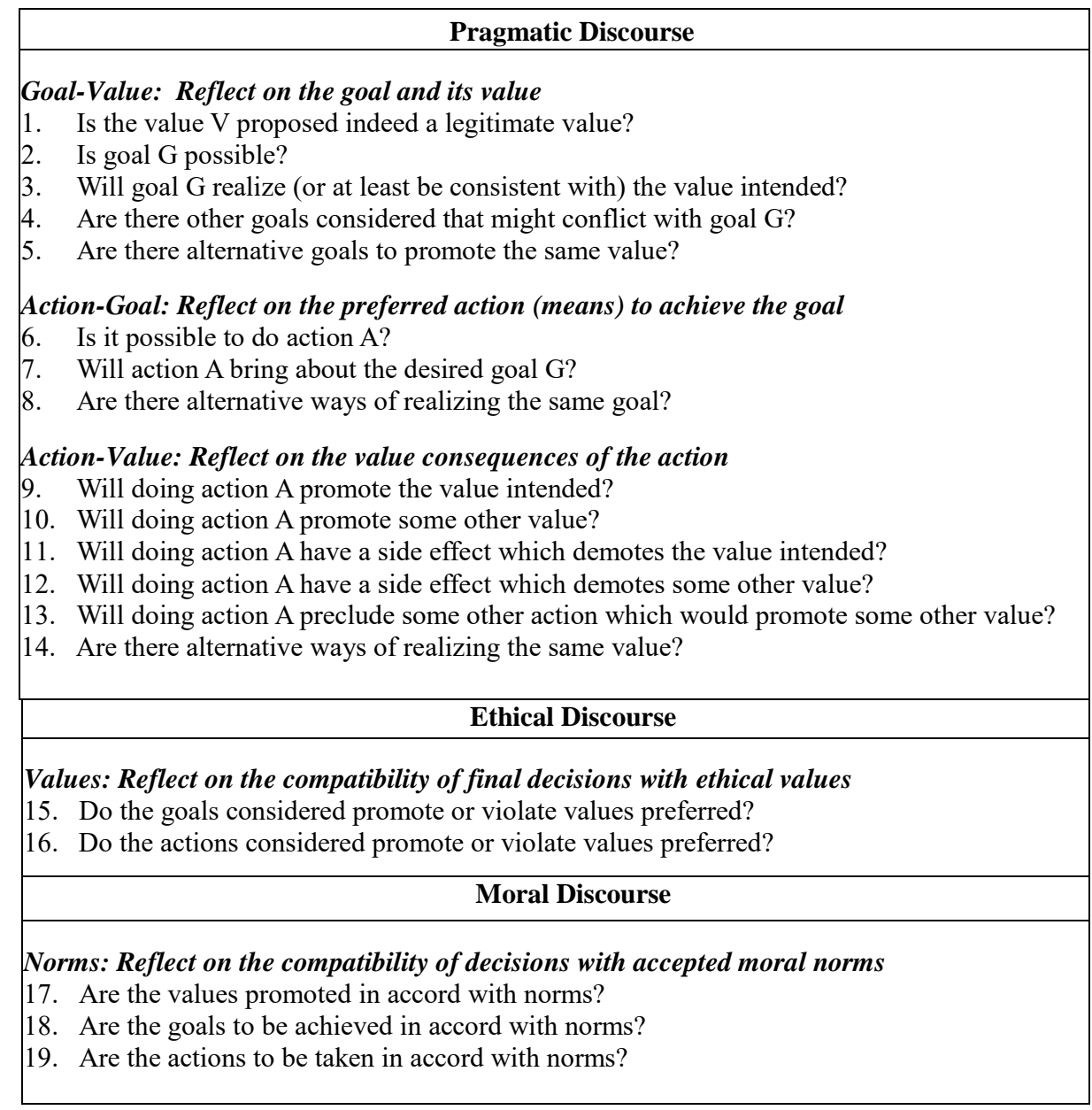

Reflections in pragmatic discourse assess the choice of means in the light of fixed goals, or of goals in the light of existing value preferences. The questions for pragmatic discourses were mainly based on the concept of value-based practical reasoning [1]. In 
the context of persuasive systems, this kind of reasoning in checking mode can support the examination of existing practices or systems.

The goal of an ethical discourse is first and foremost to critically evaluate the goodness of ends [5, p. 161). In the checking mode we considered those questions that help to assess whether the choices of goals and actions (i.e., results of pragmatic discourse) are in line with the values preferred. Two questions are included so as to critically evaluate the goodness of the results of pragmatic discourse, i.e., checking the goals and the actions taken with respect to their compatibility with the values preferred. They accommodate Habermas's [5] requirement that practical decisions should be compatible with ethical values to be considered legitimate.

Moral discourses deal with the moral rightness of norms of actions or regulations. Norms and values differ in their reference to obligatory rule-following and in their absolute versus relative bindings, as Habermas [5] states: "In the light of norms, I can decide what action is commanded; within the horizon of values, which behavior is recommended." (p. 256). Moral discourses can be entered into to find a norm or regulation that is just (identifying mode) or to assess the morally rightness of the results of other discourses (checking mode). For the checking mode we considered those questions that critically assess the results of other discourses. They can prompt researchers to examine whether the values promoted, goals set or actions taken are in accord with accepted norms and if they are in line with the requirement that the results of pragmatic and ethical discourses should be compatible with the moral norms in order to be considered legitimate [5].

To conclude, the schema recommends researchers reflect on and communicate the issues. Next, we apply these questions to analyze a research case in order to understand whether they have been inherently followed in a somewhat coherent way.

\section{An Example of Reflective Research Communication}

\subsection{Purpose and Method}

To demonstrate the applicability of the framework, we examined a published research article echoing the work other researchers [8] have done who used secondary data in the form of published cases to demonstrate the applicability of their guidelines. A published article can be viewed as an artifactual outcome of a reasoning process. We consider the article by Purpura et al. [12], which discusses some ethical and sociocultural considerations involved in the design. It thus represents a good example of reasoning on the practical issue of "what one is to do" and provides evidence for pragmatic, ethical and moral reasoning. Our main goal is to determine if the descriptions, explanations, and justifications provided by the authors are classifiable according to the concepts of the framework.

Our analysis followed interpretive research method principles [8]. We marked sentences that express concepts of the schema, i.e., goals, actions, explicit value terms (e.g., privacy, surveillance, helpful, useful), and value consequences, and interpreted them through the lens of the questions. In the presentation of the analysis, we use $\mathrm{Q} \#$ to refer to the related questions of the schema, where applicable. Indeed, multiple readings and 
interpretations of a text can be generated. The analysis draws on the text in its own right. We do not challenge its authors, nor undertake a critical evaluation of the quality of the articles. Yet, by analyzing the articles in the light of the framework we also demonstrate how authors, reviewers, and editors can apply it.

\subsection{The Fit4Life Case}

This case deals with a fictional, critical design, whose goal is not to provide a clear solution to a problem but to provoke reflection about ethical and conceptual limits of persuasive computing. For this purpose, Purpura et al. [12] first took the persuasive technology and obesity research literature at their word and implemented their logic and recommendations in a system called Fit4Life. Then they used the system as an example for reflecting on persuasive computing. The Fit4Life system "encourages individuals to address the larger goal of reducing obesity in society by promoting individual healthy behaviors." Its goal is to make users aware of situations that might negatively impact on their maintaining their ideal weight and to cause a change in their eating and exercise behaviors. The persuader is, on one level, the system designers. On another level, the Fit4Life system allows other individuals on social networks to become persuaders and influence each user (e.g. by generating wall posts to notify others to provide encouragement).

We employed the framework to analyze researchers' critical reflections on the design of Fit4Life and persuasive computing. Table 2 illustrates example statements as evidence used for the reflections relating to some of the questions. Concerning the pragmatic discourse, the researchers reflected on the societal goal of reducing obesity and the value of its achievement (Q3), i.e., improving the health of people and also making them attractive and socially acceptable. They criticized the design goals of the previous research and suggested alternative design goals to promote the same value (Q5). The researchers also argued for a design to foster mindfulness, challenged the appropriateness of existing actions for this purpose (Q7), and suggested alternative ways of achieving the desired goals effectively (Q8). Finally, they reflected on value consequences or side-effects of actions, for example, stating that the use of a specific model narrows our understanding of healthiness (Q11), that the use of a quantitative measuring method discards the value of personal experience (Q12), and that the system suggesting what to do precludes users from deciding on appropriate actions and improving their selfreflection ability (Q13).

Ethical discourse involves reflections on values and value conflicts as well as the assessment of whether actions and goals are in line with the preferred values. The example sentences illustrate researchers' evaluation/checking of Fit4Life against some accepted values. While reflecting on a broader, pervasive rationalization of our lives, they criticized Fit4Life for representing a rationalistic, objective worldview and denying our humanity (Q15), and that the mechanism used (i.e., the beacon) is coercive, forcing users to act involuntarily (Q16).

Moral discourse involves reflections on the rightness of actions or decisions. For example, the researchers raised moral issues with respect to enforcing the social good over the individual good through unpleasant pressure (Q17), setting goals for changing 
another's attitude, belief, or behavior (Q18) and using fears and anxieties as a means for achieving social goals (Q19).

We should note that multiple interpretations of a statement are possible. For example, a statement that emphasizes rationalization through a persuasive system can be interpreted from a pragmatic perspective (i.e., the effectiveness of rationalization through the system), from an ethical perspective (i.e., the goodness of rationalization through the system), or from a moral perspective (i.e., the rightness of rationalization through the system). Similarly, statements that criticize preferences for social goods (or goals) over individual goods (or goals) and vice versa may be viewed from the perspective of goodness (ethical) or rightness (moral).

In summary, the analysis illustrates how the researchers used arguments to present and justify their work that matches some of the questions in the framework, and that the main ideas of the framework are inherently considered within their research communication practice.

Table 2. Reflections on the design of the Fit4Life system

\begin{tabular}{|c|}
\hline Pragmatic Discourse \\
\hline Goal-Value: Reflect on the goal and its value \\
\hline $\begin{array}{l}\text { Q3: "Optimizing the system to achieve the user-in-societal goal of reducing obesity will not } \\
\text { only improve the health of working Americans, making them more productive, but, also has } \\
\text { the effect of helping each participant become more attractive, and, therefore, more socially } \\
\text { acceptable." (p. 424) }\end{array}$ \\
\hline $\begin{array}{l}\text { Q5: "While we used the terminology and design practices of the persuasive computing } \\
\text { movement, the complete Fit4Life product [...] highlights a need for reflection through non- } \\
\text { judgmental means rather than persuasion to achieve an ideal. In this way, it suggests that an } \\
\text { ideal system might be a subjective one that would allow users to define their own meanings } \\
\text { and values." (p. 428) }\end{array}$ \\
\hline Action-Goal: Reflect on the preferred action (means) to achieve the goal \\
\hline $\begin{array}{l}\text { Q7: "If Fit4Life were designed to foster mindfulness, it might not discuss calories, schedules, } \\
\text { and exercise in minutes at all." (p. 431) }\end{array}$ \\
\hline $\begin{array}{l}\text { Q8: "[...] exercise and diet planning regimes could be more effective }[\ldots] \text { By exposing rather } \\
\text { than covering seams [...] in the abilities of calorie or exercise tracking, [...] users would be } \\
\text { encouraged to reflect on how they feel." (p.431) }\end{array}$ \\
\hline Action-Value: Reflect on the value consequences of the action \\
\hline $\begin{array}{l}\text { Q11: "One issue with the formal models derived from sensed data used in Fit4Life is that } \\
\text { positive behavior is identified solely with reducing BMI. In choosing such a fixed model, the } \\
\text { system reinforces a narrow conception of what it means to be healthy or fit." (p. } 429)\end{array}$ \\
\hline $\begin{array}{l}\text { Q12: "By focusing on quantitative measures the system also discards the value of personal } \\
\text { experiences and emotions for a utilitarian position on the value of food and exercise." ( } p .429)\end{array}$ \\
\hline $\begin{array}{l}\text { Q13: "[The System] provides explicit verbal suggestions when } \\
\text { or avoided [...] The user no longer has to calculate calories }\end{array}$ \\
\hline
\end{tabular}


themselves whether they are within their daily calorie allowance [...] we took away the user's ability to reflect on their situation and decide on appropriate action." (p. 430)

Ethical Discourse

Values: Reflect on the compatibility of final decisions with ethical values

Q15: "Fit4Life represents an incursion of a rationalistic, objective view of the world that is often hidden in the agendas of persuasive designers. [...] By seeking to reduce basic human flaws (or characteristics [...]), the persuasive agenda embodied in this design is dehumanizing." (p. 429)

Q16: "But when viewed critically, the beacon appears as both a signal for help and an element of shame. While soliciting support for the user it also highlights his or her nonconformity to personal and social norms and an inability to stick to plan. We believe that this shame [...] is coercive [...].” (p. 428)

\begin{tabular}{l} 
Moral Discourse \\
\hline Norms: Reflect on the compatibility of decisions with accepted moral norms \\
Q17: "Fit4Life's design decisions frequently sacrificed individual good for the social good- \\
by providing avenues for unpleasant peer pressure, for example." (p. 428) \\
Q18: “More broadly, persuasive computing raises questions on the ethics of changing \\
another's attitude, belief or behavior. In considering an ethical boundary situated around a \\
user's intent we must ask if a choice can even honestly be made to take away one's choices." \\
(p. 428) \\
Q19: “[...] persuasive technologies [...] often aim to enforce sublimated social goals. Is it \\
ethical to exploit fears and anxieties in service of such goals? Are users allowed witness to the \\
origin and full extent of these changes?" (p. 428)
\end{tabular}

\section{Discussion and Conclusion}

Acknowledging that persuasive systems imply value assumptions and have consequences for those affected, previous research has already emphasized the importance of reflection and user participation in the analysis, design and evaluation of such systems. In this paper we have taken a reflective perspective and considered a reflection framework which was informed by discourse ethics, in particular by three types of practical discourses, as well as by other value-focused approaches. The framework includes a set of refined discourse-type specific guiding questions for supporting the reasoning of researchers, designers or other stakeholders in practical discourses. The questions aim to create an awareness of important aspects and to prompt discourse participants to think about them.

The demonstration of the framework by applying it to a prior case have provided evidence of its applicability as well as showing its practical relevance for communicating research results. The analysis of the article on persuasive technology shows that researchers' reflections on the main concerns - including the desirability of changing a behavior to a specific direction, the effectiveness of methods chosen, and the value 
implications - instantiate concepts of the framework such as values, goals and actions at different levels of abstraction.

This work offers several benefits to research and practice. First, it provides refined structures for documenting the reasoning of researchers throughout different stages of a project. Second, it complements general guidelines for communicating reflective research results by making dimensions such as goal-value or action-value with associated critical questions explicit, so that researchers can use the framework as a guide to reason about the content they want to communicate in different sections of an article, including the goals, actions (methods) and associated values at different levels of granularity. Third, the framework can be used for ex post analysis and evaluation of published works. By asking questions researchers can critically evaluate ideas and identify further research issues which have gained less attention or been ignored. Nevertheless, we do not argue for a too strict consideration of the questions, as this may not always be practical for different reasons, including limits to an article's length, its thematic focus, as well as the background of researchers. Fourth, this work may also be of value in a review process. Reviewers can consider the concepts and questions of the framework so as to assess the validity of a value sensitive design research study as well as the reporting of its results. In this way, the reviewers participate in and continue practical discourses leading to an agreement or a revision of the research and/or the organization of the paper's content.

The suggested questions are by no means complete. Researchers can investigate additional questions for promoting reflection and guiding research communication. Moreover, further proof-of-use analyses can follow once we see how these ideas are applied in future research publications.

\section{References}

1. Atkinson, K.; Bench-Capon, T.; McBurney, P. (2006) Computational representation of practical argument. Synthese, 152(2), pp. 157-206.

2. Davis, J.; Nathan, L.P. (2015) Value Sensitive Design: Applications, Adaptations, and Critiques. In: I. van de Poel, P. Vermaas, \& J. van den Hoven (Eds.): Handbook of Ethics, Values and Technological Design. Springer, pp.11-40.

3. Friedman, B.; Kahn, P. H., Jr.; Borning, A. (2006) Value Sensitive Design and information systems. In P. Zhang and D. Galletta (eds.), Human-computer interaction in management information systems: Foundations, pp. 348-372. New York.

4. Habermas, J. (1993). Justification and Application Polity Press, Cambridge.

5. Habermas, J. (1996) Between Facts and Norms Polity Press, Cambridge.

6. Haghighatkhah, A.; Oinas-Kukkonen, H.; Yetim, F. (2014) An Argumentation-based Design Rationale Application for Reflective Practice. In: Proceedings of the 22nd European Conference on Information Systems (ECIS), 9-11 June 2014, Tel Aviv, Israel.

7. Halttu, K.; Oinas-Kukkonen, H. (2017) Persuading to Reflect: Role of Reflection and Insight in Persuasive Systems Design for Physical Activity. Human-Computer Interaction, 32:5-6, pp. 381-412.

8. Klein, H. K.; Myers, M.D. (1999) A Set of Principles for Conducting and Evaluating Interpretive Field Studies in Information Systems. MIS. 
9. Kuonanoja, L.; Meedya, S.; Win, K.; Oinas-Kukkonen, H. (2018). Ethical Evaluation of a Value Sensitive Persuasive System: Case Milky Way. Proceedings of the Twenty-Second Pacific Asia Conference on Information Systems, pp. 1983-2825.

10. Oinas-Kukkonen, H.; Harjumaa, M. (2009) Persuasive Systems Design: Key Issues, Process Model, and System Features. Communications of the Association for Information Systems 24, pp. 485-500.

11. Ploderer, B.; Reitberger, W.; Oinas-Kukkonen,H.; van Gemert-Pijnen, J. (2014) Social interaction and reflection for behaviour change. Personal and ubiquitous computing, 18(2), pp. 1667-1676.

12. Purpura, S., Schwanda, V., Williams, K., Stubler, W., Sengers, P. (2011) Fit4Life: The Design of a Persuasive Technology Promoting Healthy Behavior and Ideal Weight. Proceedings of the 27th international conference on Human factors in computing systems. New York, NY, USA: ACM; pp. 423-432.

13. Yetim, F. (2006) Acting with Genres: Discursive-Ethical Concepts for Reflecting on and Legitimating Genres. European Journal of Information Systems 15(1), pp. 54-69.

14. Yetim, F. (2008) Critical Examination of Information: A Discursive Approach and its Implementations. Informing Science 11, pp. 125-146 (http://inform.nu/Articles/Vol11/ISJv11p125146Yetim212.pdf)

15. Yetim, F. (2011a) A Set of Critical Heuristics for Value Sensitive Designers and Users of Persuasive Systems. Proceedings of the $19^{\text {th }}$ European Conference on Information Systems (ECIS 2011), June 9-11, 2011, Helsinki, Finland.

16. Yetim, F. (2011b) Bringing Discourse Ethics to Value Sensitive Design: Pathways to Toward a Deliberative Future. AIS Transactions on Human-Computer Interaction (3) 2, pp. 133-155

17. Yetim, F. (2013) Critical Perspective on Persuasive Technology Reconsidered. Proceedings of the ACM SIGCHI Conference on Human Factors in Computing Systems (CHI-2013), 27.0.4. - 02.05.2013, Paris, ACM New York, pp. 3327-3330.

18. Yetim, F. (2016) Applicability of a Reflection Model for Communicating Value Sensitive Design Research. In: Proceedings of the 24nd European Conference on Information Systems (ECIS), 12-15 June 2016, Istanbul, Turkey. 